\title{
The Influence of Technological Factors \\ on Physico-Mechanical Properties \\ and Electrical Conductivity \\ of Copper Matrix Composite Materials
}

\author{
Alina I. Trunova* and Vladimir G. Babkin \\ Siberian Federal University \\ 79 Svobodny, Krasnoyarsk, 660041, Russia
}

Received 26.01.2018, received in revised form 29.04.2018, accepted 27.05.2018

The article was prepared on the basis of the report presented at the $9^{\text {th }}$ International Congress "Non-Ferrous Metals and Minerals-2017". The influence of the content of the strengthening phase in the copper matrix composite materials of the Cu-CrB2 system on the strength, hardness, and electrical conductivity is described. Presented of data on the change in the mechanical and electrically conductive properties of the material under elevated conditions. According to the macrostructure, the recommendations for reducing the grain size of the composite are proposed.

Keywords: copper matrix composite alloys, synthesis of reinforcing phase, strength, hardness, electrical conductivity.

Citation: Trunova A.I., Babkin V.G. The influence of technological factors on physico-mechanical properties and electrical conductivity of copper matrix composite materials, J. Sib. Fed. Univ. Eng. technol., 2018, 11(4), 427-432. DOI: 10.17516/1999494X-0065.

\section{Влияние технологических факторов \\ на физико-механические свойства \\ и электропроводность медематричных композитов}

\author{
А.И. Трунова, В.Г. Бабкин \\ Сибирский федеральный университет \\ Россия, 660041, Красноярск, пр. Свободный, 79
}

Статья подготовлена по материалам доклада, представленного на IX международном конгрессе «Цветные металль и минераль-2017». Описано влияние содержания упрочняющей фазы вмедематричном композиционномматериале системы $\mathrm{Cu}-\mathrm{Cr} \mathrm{B}_{2}$ на прочность, твердость

(C) Siberian Federal University. All rights reserved

* Corresponding author E-mail address: alina_perphileva@mail.ru 
и электропроводность. Представлены данные по изменению механических и электропроводных свойств материала при повышенных температурах. По данным макроструктуры полученных образиов предложены рекомендации по уменьшению размера зерна композита.

Ключевые слова: медематричные композиционные материаль, синтез упрочняющих фаз, прочность, твердость, электропроводность.

В качестве электродного материала наибольшее распространение получила хромовая бронза БрХ (0,5-1,0 \% Cr), которая подвергается закалке с 850-950 ${ }^{\circ} \mathrm{C}$ и последующему старению при $400{ }^{\circ} \mathrm{C}$. Выделяющаяся равновесная фаза представляет собой чистый хром. Термомеханическая обработка существенно увеличивает прочностные характеристики дисперсионнотвердеющего сплава. Однако при температурах эксплуатации хромовой бронзы выше $530{ }^{\circ} \mathrm{C}$ происходит ее разупрочнение за счет коагуляции включений хрома. Кроме того, при высоких температурах электродные сплавы могут интенсивно окисляться, образуя на торце электродов пленку. Окисление рабочей поверхности электродов, увеличивая контактное сопротивление, приводит к еще большему разогреву металла при прохождении сварочного тока и тем самым к его разупрочнению.

Бориды переходных металлов начинают окисляться при $600-700^{\circ} \mathrm{C}$, т.е. они более устойчивы, чем хром. Бориды отличаются высокой химической стойкостью в различных агрессивных средах, а также металлоподобностью, выражающейся в их высокой электро- и теплопроводности, что делает возможным их применение в качестве упрочняющей фазы в медной матрице.

Ранее нами были получены композиционные сплавы системы $\mathrm{Cu}-\mathrm{Cr}_{3} \mathrm{C}_{2}$, прочностные свойства которых при комнатной температуре более чем в 2 раза выше, чем у чистой меди [1]. Однако требования к электротехническим материалам возрастают, в частности, особенностью работы разрывных контактов является то, что в момент замыкания-размыкания контакт подвергается воздействию высоких температур. В этой связи одной из важнейших характеристик электроконтактов выступает стабильность свойств при повышенных температурах. Также важно для электропроводных материалов наличие мелкозернистой структуры, так как известно, что повышение температуры сопровождается ростом зерна.

Цель работы - получение литых медематричных композитов системы $\mathrm{Cu}-\mathrm{CrB}_{2}$ и исследование влияния технологических факторов на их структуру и физико-механические свойства.

Композиционные сплавы системы $\mathrm{Cu}-\mathrm{CrB}_{2}$ получали в индукционной тигельной печи $\mathrm{c}$ графитовым тиглем. В качестве исходного материала брали медь марки МЗ. Зеркало расплава покрывали флюсом $\left(80 \% \mathrm{CaF}_{2}+20 \% \mathrm{Na}_{3} \mathrm{AlF}_{6}\right)$ и после снятия шлака в медной фольге вводили смесь порошкообразного хрома (фракции до 1 мм). Расплав выдерживали в течение 5 мин и затем в медной фольге в него добавляли смесь порошков меди и бора для синтеза в системе борида хрома. Расплав выдерживали в течение еще 10 мин и разливали в металлический кокиль. Из полученных цилиндрических слитков готовили образцы для металлографических исследований и механических испытаний.

На рис. 1 представлена зависимость содержания борида хрома в литой меди марки М3 на предел прочности $\left(\sigma_{\mathrm{B}}\right)$.

Из приведенных данных следует, что с повышением содержания борида хрома, синтезированного в расплаве меди, прочность повышается в 1,5-2 раза по сравнению с чистой медью при комнатной и повышенной температурах. Так, для образца, содержащего $1,5 \% \mathrm{CrB}_{2}$, предел 
прочности на разрыв при температуре рекристаллизации составляет $100 \mathrm{MПа,} \mathrm{а} \mathrm{для} \mathrm{образца}$ из чистой меди - 48 МПа, что делает возможным применение данного материала для деталей, работающих при повышенных температурах эксплуатации.

На рис. 2 представлена зависимость содержания борида хрома в медематричном композиционном материале (КМ) на твердость полученных образцов и размер зерна.

Согласно полученным результатам, с увеличением содержания борида хрома повышается твердость КМ. Однако размер зерна также увеличивается. Укрупнение зерен может быть вызвано несколькими факторами. Во-первых, в процессе синтеза происходит выделение из раствора $\mathrm{Cr}$ и В в виде частиц $\mathrm{CrB}_{2}$ по реакции с выделением тепла, поэтому перегрев расплава в тигле увеличивается, что дает возможность роста зерна.

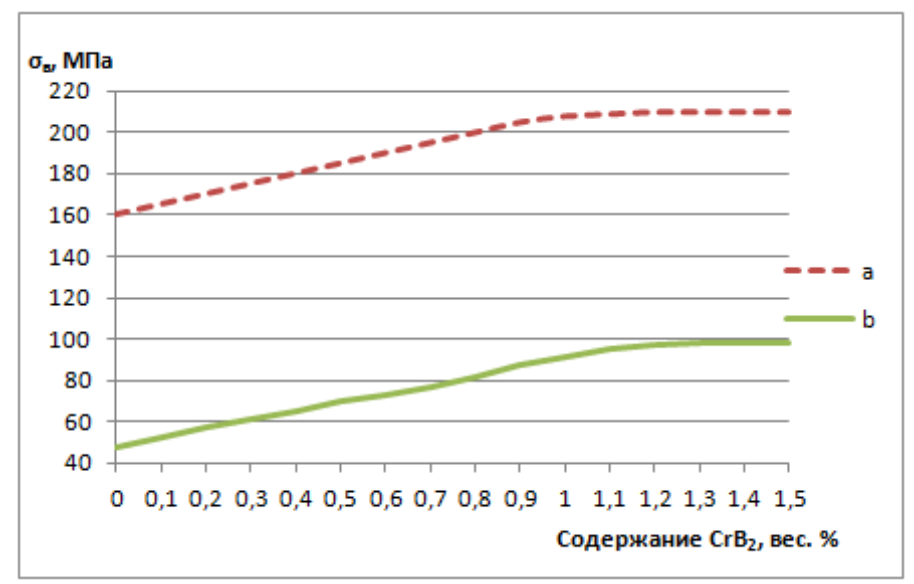

Рис. 1. Влияние содержания борида хрома в литой меди марки $\mathrm{M} 3$ на предел прочности $\left(\sigma_{\mathrm{B}}\right)$ при $20^{\circ} \mathrm{C}(\mathrm{a})$ и $350{ }^{\circ} \mathrm{C}(\mathrm{b})$

Fig. 1. The influence of the content of chromium boride in cast copper grade M3 on the tensile strength $\left(\sigma_{\mathrm{v}}\right)$ at $20{ }^{\circ} \mathrm{C}(\mathrm{a})$ and $350{ }^{\circ} \mathrm{C}(\mathrm{b})$

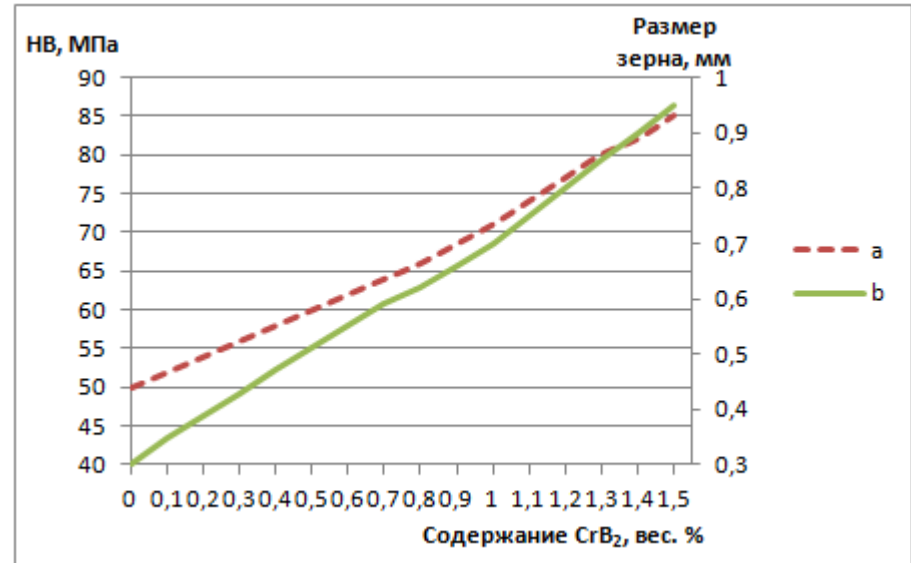

Рис. 2. Влияние содержания борида хрома в литой меди марки M3 на твердость (a) и размер зерна (b)

Fig. 2. The influence of the content of chromium boride in cast copper grade M3 on hardness (a) and grain size (b) 
Во-вторых, при нагреве и последующем плавлении медь окисляется с образованием закиси меди $\left(\mathrm{Cu}_{2} \mathrm{O}\right)$ и легкоплавкой эвтектики, которая располагается по границам зерен, ухудшая ее механические свойства и способность к пластической деформации. Основу эвтектики (светлое поле на рис. $3 a$ ) составляет твердый раствор кислорода в меди. Получение медематричного композита связано с перегревом расплава до $1250{ }^{\circ} \mathrm{C}$. При этой температуре происходит плавление $\mathrm{Cu}_{2} \mathrm{O}\left(1234,8^{\circ} \mathrm{C}\right)$ [2]. Выше температуры плавления в равновесии находятся жидкая медь, насыщенная кислородом и оксидная жидкая фаза, насыщенная медью. Жидкий оксид меди не смачивает частицы диборида хрома, поэтому возможно их укрупнение с образованием конгломератов (рис. $3 b$ ). Кроме того, жидкая медь не смачивает жидкий оксид меди, в результате чего возможна коалесценция, способствующая образованию крупных капель.

В предыдущих работах [2] методом термического анализа нами было исследовано насыщение расплава меди кислородом и возможность его раскисления наноразмерным алмазографитом, входящим в состав реакционной смеси, применяемой для синтеза карбида хрома при получении медематричных композитов. Однако на основании расчета свободной энергии Гиббса было установлено, что эффективность раскисления расплава меди бором, входящим в состав реакционной смеси для синтеза борида хрома, выше, чем углеродом:

$$
\begin{array}{ll}
\mathrm{Cu}_{2} \mathrm{O}+\mathrm{C}=4 \mathrm{Cu}+\mathrm{CO}_{2} & \Delta \mathrm{G}_{1250}^{0}=-282 \text { кДж/моль } \\
3 \mathrm{Cu}_{2} \mathrm{O}+2 \mathrm{~B}=\mathrm{B}_{2} \mathrm{O}_{3}+6 \mathrm{Cu} & \Delta G_{1250}^{0}=-708 \text { кДж/моль }
\end{array}
$$

На рис. 4 представлено влияние содержания борида хрома в литом медематричном КМ на удельное электрическое сопротивление (УЭС) меди.

Удельное электрическое сопротивление чистой меди при $20{ }^{\circ} \mathrm{C}$ составляет $1.7 \cdot 10^{-8} \mathrm{Oм} \cdot \mathrm{M}$. При увеличении содержания упрочняющей фазы до 0,5-0,7 \% удельное электрическое сопротивление меди повышается примерно на 35 \%, что является допустимым для электротехнической меди. Отметим также повышение при этих концентрациях прочности композита на $20 \%$ и на 20-30 \% твердости по сравнению с чистой медью. С повышением температуры до $350{ }^{\circ} \mathrm{C}$ электропроводность чистой меди и композита снижается в 2,2 раза, однако при этом прочность композита остается значительно выше прочности меди. Низ-

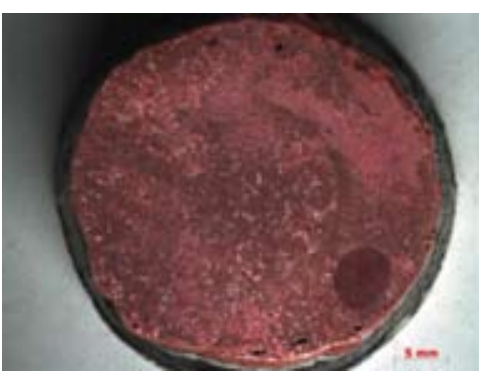

a

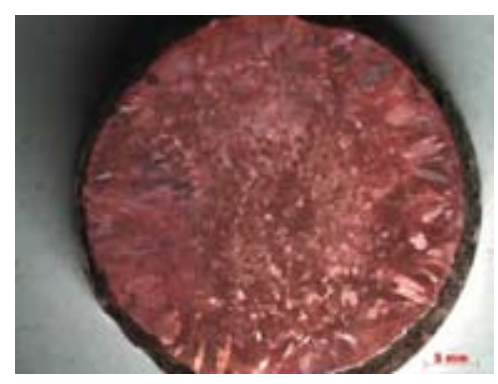

$\mathrm{b}$

Рис. 3. Макроструктура полученных образцов: a - чистая медь; $\mathrm{b}-\mathrm{KM}$ системы $\mathrm{Cu}-\mathrm{CrB}_{2}$

Fig. 3. Macrostructure of the obtained samples: $a-$ pure copper; $b-$ composite material systems of $\mathrm{Cu}-\mathrm{CrB}_{2}$ 


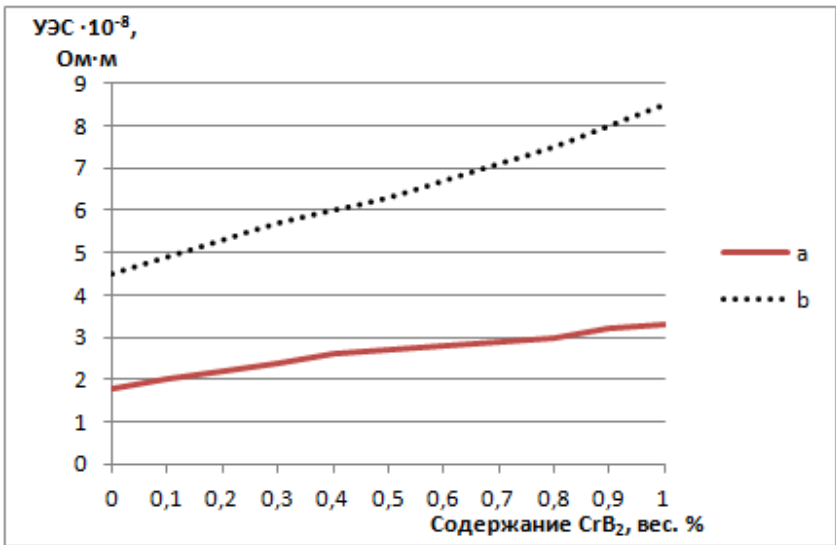

Рис. 4. Влияние содержания упрочняющей фазы на удельное электрическое сопротивление меди при $20{ }^{\circ} \mathrm{C}$ (а) и при $350{ }^{\circ} \mathrm{C}(\mathrm{b})$

Fig. 4. The influence of the content of the strengthening phase on the electrical resistivity of copper at $20^{\circ} \mathrm{C}$ (a) and at $350{ }^{\circ} \mathrm{C}(\mathrm{b})$

кая прочность меди связана с наличием эвтектики по границам зерен (рис. $3 a$ ), а в композите часть бора идет на раскисление меди. Чтобы не происходило потерь бора, требуется тщательное раскисление, например, с применением борсодержащей лигатуры. Отсутствие эвтектики по границам зерен будет способствовать повышению прочности меди при повышенных температурах, а наличие упрочняющей фазы будет повышать температуру ее рекристаллизации.

\section{Выводы}

1. С повышением температуры до $350{ }^{\circ} \mathrm{C}$ резко снижается прочность чистой меди изза наличия легкоплавкой эвтектики, расположенной по границам зерен; при этом прочность дисперсно-упрочненного КМ на основе меди тоже снижается, однако ее значения более чем в 2 раза выше по сравнению со значениями чистой меди. Наличие упрочняющей фазы способствует повышению температуры рекристаллизации меди.

2. С увеличением содержания упрочняющей фазы снижается удельная электрическая проводимость меди. При повышении температуры до $350{ }^{\circ} \mathrm{C}$ электросопротивление чистой меди повысилось на 40 \% и на 42 \% - упрочненной частицами диборида хрома, при этом значения прочности КМ выше по сравнению с чистой медью.

3. Увеличение размера зерна связано с выделением тепла в процессе реакций образования боридов хрома. Прочность и электропроводность можно повысить за счет измельчения зерна. Улучшить структуру можно двумя способами: 1) быстрое охлаждение с температуры синтеза боридов (литье в водоохлаждаемый кокиль); 2) перегрев расплава до гомогенного состояния и последующее быстрое охлаждение. Температуру перехода расплава в гомогенное состояние можно снизить, модифицируя его редокоземельными металлами (в составе мишметалламодификатора, выпускаемого промышленностью).

4. Предложенные рекомендации будут опробованы в следующей серии экспериментов. 


\section{Список литературы}

[1] Бабкин В.Г., Терентьев Н.А., Перфильева А.И. Литые металломатричные композиционные материалы электротехнического назначения. Журнал СФУ. Техника и технологии, 2014, 4, 416-423 [Babkin V.G., Terentiev N.A., Perphileva A.I. Cast Metal Matrix Composite Materials of Electrotechnical Purpose. J. Sib. Fed.Univ.Eng. technol., 4, 416-423 (in Russian)]

[2] Бабкин В.Г., Трунова А.И., Черепанов А.И. Влияние кислорода на механические свойства меди и медематричных композитов, упрочненных синтезированными в расплаве карбидами хрома. Металль, 2016, 3, 25-30 [Babkin V.G., Trunova A.I. Cherepanov A.I. The effect of oxygen on the mechanical properties of copper and copper matrix composites reinforced by chromium carbides synthesized in the melt. Metals, 2016, 3, 25-30 (in Russian)] 